\title{
Instilling Environmental Awareness into Literature Teaching
}

\author{
Shaojun Duan* \\ School of Foreign Languages \\ Kunming University \\ Kunming, China \\ duanshaojun2709@126.com
}

\begin{abstract}
With the rapid development of economy and technology, the contradiction between environment and society dashes forward. In this case, establishing an environmental awareness in people's mind esp. in the minds of college or university students has become a major theme of the time. This article attempts to enlighten the environment protection consciousness and to explore practical methods of environment protection by analyzing Emerson's concept about nature in his masterpiece "Nature", and by relating to the reality of Chinese harmonious development in American literature teaching class so as to stir up an environmental awareness in the minds of college or university students.
\end{abstract}

Keywords-environmental awareness; literature teaching; Emerson's concept of nature; Chinese harmonious development; environmental protection measures

\section{INTRODUCTION}

With the rapid development of economy and technology, the contradiction between environment and society dashes forward. In this case, establishing an environmental awareness in people's mind esp. in the minds of college or university students has become a major theme of the time. In American literature teaching, we will encounter Emerson, the great poet of American romanticism who was the representative of transcendentalism. For teachers, this is a good chance to spread Emerson's concept of nature among students and help them to establish the environmental awareness through learning the great writer's masterpiece "Nature" and relating to the reality of Chinese harmonious development as well, even to point out the road to realize environment protection for students in a further step.

\section{EMERSON'S CONCEPT ABOUT NATURE}

\section{A. Nature's Influence on Human Beings}

The contemporaries' ever-changing life is driven by continuous advances of productivity. But many progresses were made in the cost of natural resources. Early in the 19th century, Emerson had realized it. There is no doubt that he is a prominent forecaster. "In his opinion, nature is ennobling, human beings and nature are closely knitted. Nature is the root of one's life."[1]23 He once said: "Nature never wears a mean appearance. Neither dose the wisest man extorts all her secret, and lose his curiosity by finding out all her perfection. Nature never became a toy to a wise spirit."[2]165 From this quotation we can see that Emerson consider that nature owns an unimaginable power that is unparalleled and inviolable. "Standing on the bare ground, my head bathed by the blithe air, and uplifted into infinite space, —all mean egotism vanishes. I become a transparent eye-ball; I am nothing; I see all; the currents of the Universal Being circulate through me; I am part or particle of God. " [3]30 Nature and human beings are as a whole, the rule of nature and men are similar. It illustrates that man are characterized with divinity and integrity, with nature man could break up the bondage of their physical body and be a transparent eye-ball to see the beauty of nature. Man as a member of living creatures, harmony, equality and integrity are the basic principles to raise man above other creatures.

Maybe different people will perceive quite unlike feelings from the same landscape. One could have an insight of common beauty but the other may neglect it. To Emerson, natural beauty lies in itself, and more important, it is closely related to human being's emotion. Nature for man is an object, but when you approach to it, you'll be affected by its appearance, feeling exalted or depressed it all depends on your interior state. That is to say, beautiful sight doesn't simply mean the fairness of nature but the combination of viewer's internal state and external environment. It proves that men have a good sense of subjective initiative. By using it, men can make a full play of nature. However, few contemporaries realized it. They just treat nature as common things. For them, grass, flower and streams are so normal, so they never pay more attention to them.

\section{B. The Inherent Connection between Man and Nature}

Put emphasis on the communication between nature and men and help the latter to be spiritual civilized. In this sense, human beings is part of nature, they are beneficiary of enjoyment, comfort, and beauty of nature. "The sun illuminates only the eye of the man, but shines into the eye and the heart of the child.”[2]165 In other word, men perceive their soul sparks, which are illuminated by the dynamic relationship between men and nature. Human beings should hold their pure heart to feel natural instincts, regardless of their aging changes and their surroundings. Emerson made a perfect unification of two sides, and he created a harmony realm for the soul. "Connection with nature is essential for a person's intellectual, aesthetic, and moral health and growth. All are needed by each one; nothing is fair or good alone.”[3]30 The true beauty lies in unification, 
none isolated thing could be called as beauty. The same goes to nature and human beings. Man's aesthetical attitude toward nature mainly due to the inner communication between man's subjective understanding of natural sceneries with nature.

On the contrary, people seldom see such a rosy picture and experience such an ideal world. In fact, it is not rare to see environment pollution, to feel global warming and to be worried about resource exhaustion. People have to pay for their irresponsible deeds. So Emerson's nature concept is of great importance to the modern world since that obvious divergence does exist between nature and men. The two sides are connected naturally. Human beings are linked with nature from the moment they were born. Their living depends on nature, so it is impossible to cut up ties completely from it.

\section{Harmonious Living for Nature and Man}

Emerson call on people to go back to nature, for in his opinion, nature brings inner excitements and encouragements to them. On this occasion, man's thoughts will be elevated, souls be purified, instincts be beautified. Returning to nature realm can help man reconstructing harmony with it. Only in this way, human beings can regard nature as close friend. Respect it, care about it and make their friendship last forever.

Nature and man have mutual effects; nature reflects men's inner world and men comprehend it. According to what discussed above, it's not hard for us to see that in Emerson's opinion, nature is closely linked with man. The beauty of nature will be lost if it departed from man's thoughts. Man live on nature, nature brought up man, balanced world can be made.

If men want to make use of nature efficiently, they should endeavor to keep the integrity and the innate character of nature. Inside every solitary creature, there is a passion for living. Human beings who are intelligent and kind are the translator of creatures' inside world. They realize the truth of living with nature harmoniously. Natural land is not the area that men strive to conquer and rule, but our families and companies. Both men and nature need cooperate with each other so that they can develop sustainably. Men have right to satisfy their own need by changing the state of materials but they can't destroy nature's rules. Living creatures have the equal right to live in the world with men. What differs them from man is that they will not take advantages over nature. Men could be the user of nature rather than destroyer.

Men are advanced creatures in some degree, so we have the ability to care about nature and prevent it from being destroyed. It's a kind of irresponsible behavior if men think little of nature and impose force on it .Our contemporaries need to transcend from our own narrow field of vision and show indispensable respect to nature. Men and nature live in the same world, we should share it with nature, and otherwise it's difficult to live for long-term.

Never trodden the right of nature and try to preserve their interests. Emerson's view concerns about long-term interests of human beings and nature. Obviously, his opinions are significant for solving environmental problems. He insists that "men should discover the wisdom of nature through their contacts".[4]260It's the high time for our contemporaries to focus on bettering environmental condition and unifying with it.

\section{REALITY OF CHINESE HARMONIOUS DEVELOPMENT}

Being Harmonious viewpoint of China lays stress on the harmony between man and nature, which holds a firm and positive belief that man can realize their own value by unifying with nature. At this point, it fits well with Emerson's nature concept.

\section{A. The Connotative Meaning of Chinese Harmonious} Development

Harmonious viewpoint of China refers to the unity of men and natural world and aims at strengthening people's consciousness of developing harmony with nature. Applying scientific technology to explore nature should base on the condition that man should obey law of nature.

In fact, ideas of environmental protections are budded early in China. Dating back to ancient time, many scholars had realized that man and nature is a whole unity of living. For example, Zhuangzi proposed that Heaven, Earth and I come into being together, and all things and I are one. Mencius advocated that grains and fish can't be wasted too much and woods can't be cut down for unnecessary use. Ancients' arguments are similar with the main idea of Chinese harmonious development which advocated that natural resources are precious for man. Wasting resources at man's will is not only devastating the future of nature but also man's living source. Everything in this unity is related, reposed and merged. Human beings are the product of nature so they must rely on nature so that they could live and develop. Since the time man was born in the world, he takes in oxygen, water and food from natural world and he produces and excretes wastes into nature at the same time. That is to say, man is a member of all living creatures and can't depart from nature throughout his life. Nature and human beings keep a balanced relationship in the course of development.

\section{B. Man's Responsibility of Maintaining Good Environment Condition}

Actually, man can't live once they departed from natural environment, which influences man's state of mood, physiology and health. So, it is especially important for man to maintain the good quality of their surroundings. "Either living environment or working environment is a guarantee for human beings to make all-round development."[5]15 Harmonious Development of China aims at creating a society that fills up with happiness for everybody. Emerson's nature concept also emphasize that man should build up relationship with environment. Because nature endows the brightness for human beings. In nowadays, harmonious society tries to make each citizen feel happy. General happiness is the principle and ultimate purpose of the harmonious society. It requires that we should reflect man's irresponsible deeds.

Pursuing for the harmonious development is rational when facing ecological crisis. Exorcises urgently demand man pay attention for the coexistence with nature. We can't let highlydeveloped civilization reverse to the backward state nor can we be too optimistic and insensitive to make it worse. We should give affirmation for the possibility of harmony between human beings and nature. Enhancing people's initiative and advocating people's activities is very important. Global environment crisis doesn't mean people's initiative has 
produced the best possible result. On the contrary, it proves that there is a great potential for us to make efforts in protecting and improving environment conditions. In this progress, human beings should use their initiative reasonably and scientifically getting rid of the wrong concept of man is almighty but nature is inferior. In other words, constructors need to take the orders of nature into consideration. The law of nature is sacred and man can't violate it.

\section{Man and Nature Are Unified}

"Both man and nature are the members of harmonious society, existing as integrity.”[6]102 Communication of them is based on natural materials. Bountiful resources and healthy ecosystem are the precondition of sustainable development of harmonious society. Other goals of harmonious society also need to get support from nature. Such as improvement of living conditions, justice, security, vigor of society and so on. If man can't live friendly and equally with nature they will destroy harmonious society by themselves. Imaging that if people can't feed themselves without enough food, no land to live in and no clean water to drink, how they can live regardless to say constructing harmonious society. It is similar to tall trees without leaves, dim and overshadowed.

Man must respect nature at first, then explored. But do not dream to control it in the future. The deep meaning of harmonious society is mingled with the beauty of man and nature. Man is more intelligent and thoughtful than nature, so we should take our younger generations' future into account. Natural resource is not exhaustible and human beings are not omnipotent either.

\section{EnVironmental Protection Measures}

Even though it is a long road for people to make efforts to protect environment and much still remains to be done, we must try to make prospect into realization. However, in the recent years, man has made much progress on this road, for they begin to focus on environmental problems. It is undoubtedly a good beginning.

First of all, man should abandon "anthropocentric doctrine" thoroughly, setting up the concept of harmony and joint the development of the society. As Emerson wrote in Nature: "Yet it is certain that the power to produce this delight, does not reside in nature, but in man, or in a harmony of both.”[7]95 Human beings are not the ruler of nature but members of nature. They should be kind and honest and civil to natural world if they want to live in it with delight. The creatures of nature are not slaves of man and they were not born for man in service. They are equal to be members in the big nature world just the same as human beings. So, nature and man are connected in nature, the relationship between them is the nearest and dearest rather than alienated and indifferent. That is man and nature form a unified entity, sharing the pleasures of harmony. The reason why delight resides in man is that man's feelings are elevated by the beauty of nature and images in man's head are mixtures of subjectivity and objectivity. Human being's emotion is due to the blue sky, green land, sea winds, which belongs to man and nature at the same time. In this case, man get enhancement of their spirit. It sounds normal and easy but it needs man to make up their mind to be truly faithful to nature.
Next, according to the proposal of our nation, the use of man's initiative should come into beings on the basis of obeying the objective rules of nature. It requires that man should be skillful in dealing with the relationship with nature and be wise in using initiative to explore natural resources. Therefore, high technology plays an important role in balancing the relationship between man and nature. Taking advantages of high technology is essential to recycling. It is a practical way to reduce the wasting of resources. By using it, the quantity of the sewage would be deceased, the emissions of automobiles would be lowered and the release of carbon dioxide would be reduced. Moreover, it cuts down costs and saves the necessary materials for human beings at the same time. The development of high technology marks a great advance in dealing with the relationship between man and nature. Because of the effective ways and innovative practices provided by it, man could look forward to the brightness of harmony.

What's more, as nobody is perfect, we need set a series of measures as ethic criterion for human beings. Sound associations for supervising and administering needed to be set up to praise the advocates and to punish the destructors. The protection of environment includes two aspects: prevention and improvement. Prevention for the underlying threat of the environment and improvement for the damages caused. It's a public and social task. And its complexity and seriousness require people to deal with the rubbishes of daily life in details. Do not think any virtue trivial, and so neglect it . If everybody has such an attitude toward environment, pollution would be getting more and more serious. So, everybody should bear the responsibility to care about environment and put their consciousness into practice, such as saving a drop of water, minimizing the electricity usage and planting more trees and flowers. Although they may be trifle, they will assemble strength for man. Just as an old saying goes: Great things may be done by mass effort. In addition to our legal and administrative supervisions, publics' consciousnesses of participating in environmental protection should be strengthened also. In this sense, various methods of media can be used effectively to promote publics' motivations of protecting environment. Advertisements are one of the useful ways in that it is closely related with publics' daily life. They are always affected by advertisements, which are visualized, penetrating and amazing, made deep impressions on people. So it's an effective way to evoke people's consciousness. A journey of a thousand miles begins with a single step. People should take actions immediately so that the quality and quantity of the improvement can be seen soon after. We would see the trickle become a stream, the stream become a torrent one day. Stick with it and be persistent, we could see remarkable improvements.

Last but not the least, little things make life great. In the road to protect environment, man needs to pay attention to the details of life. For example, consumers should change consumption idea, choosing green products and disposing consumer waste reasonably. Laying stress on saving energy and resource while pursuing for a wealthy material life. Do to not use the plastic bags, preventing plastic pollution. Help people to cultivate civilized living habit. Do not smoke in 
public places, nor burn fallen leaves and any poisonous waste. Please do not optionally throw out the resource of recycling. For example, papers, waste plastics and old metals, which can be melted and made into new metal, are all good sources that can be recycled. It is much better if families are good at classifying garbage. Minimizing uses of throwaway chopsticks and cups which are large consumption and a great burden to nature.

\section{CONCLUSION}

In recent years, environmental problems have attracted an increasing attention across the world. Freshwater shortage, global warming, climate change, endangered species, environmental degradation and so on have become the most talked-about issue. With the decreasing quality of environmental conditions, people are anxious about the coming days. Environmentalists made great contributions on the road of environment protection, our scholars and national leaders also occupy an important position in this campaign. In this situation, it's meaningful for teachers to spread Emerson's concept of nature among students and help them to establish the environmental awareness through learning the great writer's masterpiece "Nature", even point out the road to realize environment protection to students in a further step in American literature teaching class.

\section{REFERENCES}

[1] L. Kuanhong. "To Pursuit the Spirit Value of Nature-An Analysis on Emerson's Thought about Nature and its Practical Meaning from the Sight of the Existentialis m," in Science culture and technology culture, vol. XXVIII, H. Zhiqiang Eds. Beijing: Journal of Dialectics of Nature, 2006, pp. 22-25.(in Chinese)

[2] W. Weiren. History and Anthology of American Literature. Beijing: Foreign Language Teaching and Research Press, 2007.

[3] R. .W. Emerson. Selected Essays and Addresses. New York: The Macmillan Company, 1927.

[4] W. Blare. Emerson Essays-Nature. Letchworth: The Temp le Press, 1949.

[5] J. Chang. "Harmonious Society and Elegant Survival," in Seminar, Vol. III, Y. Yong, Eds. Beijing: Philosophical Trends, 2005, pp. 3-5.(in Chinese)

[6] Q. Mansu. Emerson and China - reflections on individualis m. Beijing: Life Reading New Knowledge Joint Publishing Company, 1996.

[7] D. Van Leer. Emerson's epistemology-the argument of the essays. Cambridge: Cambridge University Press, 1986. 